\title{
Biological targets in the treatment of rheumatoid arthritis: a comprehensive review of current and in-development biological disease modifying anti-rheumatic drugs
}

\author{
This article was published in the following Dove Press journal: \\ Biologics:Targets \& Therapy \\ 3 October 2009 \\ Number of times this article has been viewed
}

\author{
Manil Kukar' \\ Olga Petryna' \\ Petros Efthimiou ${ }^{2}$ \\ 'Rheumatology Division, Lincoln \\ Medical and Mental Health Center, \\ New York, NY, USA; ${ }^{2}$ Lincoln Medical \\ and Mental Health Center, Weill \\ Cornell Medical College, New York, \\ NY, USA
}

\begin{abstract}
Enhanced understanding of the rheumatoid arthritis (RA) pathophysiology and the role of cytokines has enabled the development of innovative biological agents in the last 10 years that target specific parts of the immune response. Failure to achieve adequate response with traditional disease modifying anti-rheumatic drugs (DMARDs) and increasing evidence of ongoing radiographic deterioration of the affected joints despite seemingly clinical response were essential stimuli for the development of biologics. The current and upcoming biological agents are primarily aimed at neutralizing circulating and cell-bound pro-inflammatory cytokines, interfering in the interaction of antigen-presenting and T-lymphocytes, eliminating circulating B-lymphocytes or by interfering with the intracellular signaling mechanisms of immuno-competent cells that lead to inflammation. These agents have improved the currently available treatments due to greater efficacy, fast action and greater tolerability. However, use of these agents has also been associated with significant, although rare, adverse events and considerable cost. Therefore, these agents should be used with caution by experienced clinicians. The present work aims to provide a global and updated review of the current and in-development biological DMARDs for the treatment of RA.
\end{abstract}

Keywords: biological agents, rheumatoid arthritis, immunomodulators, treatment, cytokines

\section{Introduction}

The introduction of biological agents has dramatically altered the therapy for patients with rheumatoid arthritis (RA). Advances in the current knowledge of cytokine milieu in RA pathogenesis have contributed to the development of biological agents, and translated research findings into clinical practice.

Well established currently available biological agents include three tumor necrosis factor alpha (TNF- $\alpha$ ) inhibitors (infliximab, etanercept, adalimumab), an interleukin-1 (IL-1) receptor antagonist (anakinra), a B-cell-depleting agent (rituximab), and an inhibitor of T-cell costimulation (abatacept). TNF inhibitors were the first biologics to be added to the therapeutic arsenal; more recently the US Food and Drug Administration (FDA) approved biologic agents with different modes of action. TNF inhibitors have proved to be very effective in patients not responding to traditional disease-modifying anti-rheumatic drugs (DMARDs). However, about 20\% to $40 \%$ of patients treated with a TNF inhibitor fail to achieve a $20 \%$ improvement in American College of Rheumatology (ACR20) criteria, and more lose response over time, due to secondary failure or acquired therapeutic resistance and some experience adverse events following treatment with a TNF inhibitor. ${ }^{1}$ Two recently approved agents, certolizumab pegol and
Correspondence: Petros Efthimiou Chief, Rheumatology Division, Lincoln Medical and Mental Health Center, $234 \mathrm{E}$. 149th Street, NY, NY 1045I, USA

$\mathrm{Tel}+\mid 7185796131$

$\mathrm{Fax}+\mathrm{I} 7185794836$

Email petrosefthimiou@gmail.com 
golimumab, have increased the number of available choices in the already existing class of TNF inhibitors.

Recently, several new agents have been reported to be in various stages of development and, if approved by regulatory authorities, may cause a major shift in the therapeutic paradigm of RA.

This paper provides a comprehensive review of the current and in-development biological DMARDS.

\section{Methods}

Information was derived from PubMed, and the clinical trials registered in Clinicaltrials.gov and database of systematic reviews and relevant congress abstracts up to and including May 2009. We systematically reviewed all the published and ongoing randomized controlled trials, to evaluate the efficacy, safety, and tolerability of the current and in-development biologics. Animal studies were excluded. The primary measure of outcome evaluated in most of the studies included improvement according to the ACR20 criteria, 28-joint Disease Activity Score (DAS28) score, Health Assessment Questionnaire (HAQ) score, and health related quality of life (HRQoL). Evidence of effectiveness has been summarized using the primary end points used in the studies identified. In addition, the most frequently reported adverse events have also been weighed against the benefits of the current and upcoming biologics.

No external sponsor was involved in this study. No persons other than the authors of this manuscript were involved in the design, analysis, and interpretation of data, in the writing of the report, and in the decision to submit the article for publication.

\section{First-generation TNF- $\alpha$ inhibitors Infliximab (Remicade ${ }^{\circledR}$ )}

Infliximab is a chimeric antibody that binds both transmembrane and circulating TNF- $\alpha$. Its half-life of 8 to 10 days prompts its administration every 4 to 8 weeks at a dose of 3 to $10 \mathrm{mg} / \mathrm{kg}$ infused intravenously. Based on the ATTRACT trial which included 428 patients resistant to MTX (MTX) with a mean disease duration of 11 years, infliximab proved to be beneficial when used in combination with MTX as it halted progression of joint damage both in clinical responders and non-responders. An obvious mechanism justifying the results is the hindering of TNF action on bone resorption and the blunting of TNF effect on synthesis of cartilage proteoglycan. ${ }^{2}$ Moreover, it was recently shown that impedance of joint damage in RA can also be attributed to infliximab's effect on decreasing synovial infiltrates early after initiation of treatment by inhibiting cell migration and not by inducing apoptosis. ${ }^{3}$ Subgroup analysis of ATTRACT trial showed that radiographic stabilization of the disease was evident even in patients with early RA (ie, less than 3 years). ${ }^{4,5}$ Furthermore, greater baseline joint damage correlated with poorer physical function at baseline and less improvement in physical function after treatment suggesting that early intervention may be required. This question was to be addressed by the ASPIRE trial that included 1004 patients with disease duration less than 3 years. Indeed, infliximab infusion along with MTX in a treatment naïve population improved clinical signs and symptoms, functional outcomes and prevented structural damage of the joints significantly more than MTX monotherapy. ${ }^{4}$

An important Dutch study (BeSt), examined the efficacy of initial combination therapy versus monotherapy, involving 508 patients with newly diagnosed RA and comparing different treatment strategies. Sequential monotherapy (Group 1) and step-up combination therapy (Group 2), both starting with MTX, were compared with initial combination therapy consisting of a tapered high-dose prednisone, MTX, and sulfasalazine (SSA) (Group 3) and with initial combination therapy consisting of MTX and infliximab (Group 4). After 2 years of treatment, the goal of a DAS44 2.4 was reached by $82 \%$ in infliximab group comparing to $75 \%$ of patients in group 1, $81 \%$ in group 2, and $78 \%$ in group 3 . More patients in combination groups 3 and 4 had been able to taper and discontinue drugs of the initial combination therapy because of continuous low disease activity, given 54\% of patient receiving infliximab + MTX combination therapy tapered their treatment to monotherapy, compared to $36 \%$ in prednisone/MTX/SSA group. After 2 years of treatment, $80 \%$ of all patients achieved the goal of DAS 2.4 , and $42 \%$ reached clinical remission (DAS $<1.6)^{6}$

Another randomized controlled trial (RCT) in 20 patients with poor prognosis RA identified by Persistent Inflammatory Symmetrical Arthritis (PISA) score system and who had symptoms less than 1 year demonstrated a beneficial effect of infliximab and MTX introducing the concept of remission induction and maintenance therapy borrowed by oncology treatments. ${ }^{7}$ Furthermore, this study successfully demonstrated an arrest of the inflammatory bone loss in this patient population. ${ }^{8}$

\section{Etanercept $\left(\right.$ Enbrel $\left.^{\circledR}\right)$}

Etanercept is a fully human, soluble fusion protein created by the linkage of two ligand binding regions of p 75 TNF- $\alpha$ receptor and the Fc portion of human IgG1, and possess the 
shortest half life (3 to 4 days) of all the TNF- $\alpha$ inhibitors. Etanercept has unique properties that distinguish it from infliximab and adalimumab. In contrast to other anti-TNF agents, it also binds lymphotoxin-alpha (otherwise known as TNF- $\beta$ ) which has been associated with tumor growth control independent of TNF activity. ${ }^{9}$ In addition it does not lyse the cells expressing transmembrane TNF in the presence or absence of complement. Etanercept was approved by the FDA for use in the treatment of adult RA in 1998. Although frequently administered along with MTX in the clinical practice, etanercept has been approved as monotherapy and does not have to be co-administered with MTX. ${ }^{10}$

Moreland et al first evaluated the efficacy of etanercept monotherapy in a phase II RCT, recruiting 180 patients with refractory RA for 3 months. A dose dependent reduction in disease activity was seen, with $75 \%$ of the high dose group achieving ACR20 responses as compared to $14 \%$ in the placebo group. ${ }^{11}$ Subsequently, the results were confirmed by a phase III trial comparing two doses of etanercept (10 and $25 \mathrm{mg} \mathrm{sc}$, twice weekly). Both doses proved to be more effective than placebo and the $25 \mathrm{mg}$ dose was more effective than the $10 \mathrm{mg}$ dose. ${ }^{12}$

Combination of MTX and etanercept in active early RA (COMET) trial compared remission and radiographic nonprogression in patients treated with MTX monotherapy or with MTX plus etanercept. The observed analysis suggested $50 \%$ of the patients on combination therapy with etanercept and MTX successfully achieved clinical remission of the primary endpoint (DAS28 score) as compared to 28\% taking MTX alone. Furthermore, the halting of radiographic progression was seen in $80 \%$ patients on combination therapy, compared to 59\% patients taking MTX monotherapy. ${ }^{13}$

In one of the major biologic trials (TEMPO), a double blind, parallel-group, global study, 686 subjects were randomized to etanercept ( $25 \mathrm{mg}$ twice weekly), MTX (up to $20 \mathrm{mg} /$ week) or a combination of etanercept and MTX. Primary radiographic end point was change in the van der Heijde-modified total Sharp Score (TSS) at 52 weeks. Secondary radiographic endpoints were: changes in total erosions, changes in total joint space narrowing, number of eroded joints, non-progression (TSS change $\leq 0.5$ and $\leq 3.0$ ) and progression greater than the smallest detectable difference. Two observers, blinded for the sequence of the films, treatment mode and patient identity scored each X-ray.

Results of the TEMPO trial demonstrated that $74.2 \%$ RA patients treated with etanercept plus MTX experienced no progression of joint damage. In comparison, only $65.5 \%$ and $59.2 \%$ of etanercept monotherapy and
MTX monotherapy-treated patients respectively, had no radiographic progression of joint damage at 2 years. ${ }^{14}$

\section{Adalimumab (Humira ${ }^{\circledR}$ )}

Adalimumab is a recombinant human IgG1 monoclonal antibody specific for human TNF- $\alpha$. It not only inhibits the binding of TNF- $\alpha$ to its receptors, but also lyses cells expressing membrane bound TNF- $\alpha$ in the presence of complement. Adalimumab has an estimated half life of 6 to 14 days and can be used as monotherapy or in combination with MTX for RA. ${ }^{10}$

These results are also supported by a prospective singlearm intervention study, wherein 59 patients with established RA treated with fortnightly injections of subcutaneous $40 \mathrm{mg}$ adalimumab for 6 months reported significant improvements in the following: perceived work ability [Work Ability Index (WAI)], quality of life [Rheumatoid Arthritis Quality of Life instrument (RAQoL)], and fatigue [Checklist Individual Strength (CIS)]. ${ }^{15}$

A 2-year double-blind RCT (PREMIER) evaluated the efficacy of combination therapy of adalimumab plus MTX against MTX or adalimumab monotherapy in 799 patients with early active RA. Results after 1 year of therapy demonstrated achievement of ACR50 responses in $62 \%$ of patients treated with combination therapy as compared to $46 \%$ and $41 \%$ of patients receiving MTX or adalimumab monotherapy respectively $(P<0.001)$. Furthermore, after 2 years of treatment, $49 \%$ of patients receiving combination therapy achieved disease remission (DAS28 $<2.6$ ). Adalimumab in combination with MTX was also found to be more effective than either monotherapy in slowing the radiographic disease progression. ${ }^{16}$ The superior efficacy of adalimumab plus MTX over MTX monotherapy has also been demonstrated in a recent double-blind RCT in Taiwanese patients with active RA. ${ }^{17}$

The ARMADA trial, a 6 month placebo controlled, phase II/III study with 271 enrollees, demonstrated significant reductions in the signs and symptoms of RA, improvement in physical function, and the safety of adalimumab plus MTX vs placebo plus MTX. At 24 weeks, the combination treatment arm (adalimumab plus MTX) had significant higher ACR responses (ACR20: 67\%, ACR50: 55\%, and ACR70: 27\%) compared with $15 \%, 8 \%$, and $5 \%$, respectively, in patients who had received placebo + MTX $(P<0.001) .{ }^{18}$

In conclusion, adalimumab demonstrated significant and sustained reduction in signs and symptoms, inhibition of radiographic progression, but and also improved functional status, quality of life and work productivity in patients with RA. 
Newly approved TNF- $\alpha$ inhibitors Certolizumab pegol (Cimzia $\left.{ }^{\circledR}\right)$

Certolizumab is the first and only pegylated Fc-free anti-TNF agent which possesses a unique structure that does not include a crystallizable fragment $(\mathrm{Fc})$ portion present in the other anti-TNF $\alpha$ agents, and have a unique way of signaling through the membrane TNF. Unlike other TNF-a inhibitors (infliximab, adalimumab, etanercept), which contain an Fc region, certolizumab is not capable of mediating antibody-dependent cell-mediated cytotoxicity (ADCC) and complement-dependent cytotoxicity (CDC). ${ }^{19}$

Efficacy in RA has been shown, when used as an add-on therapy to MTX, providing long-term improvement in physical function, HRQoL, and pain relief. It has been evaluated by two phase 3, double-blind RCTs. ${ }^{20,21}$ Smolen et al followed 619 patients for a period of 24 weeks and noticed that the patients in certolizumab pegol 200- and 400-mg groups achieved ACR20 response rates of $57.3 \%$ and $57.6 \%$, respectively vs $8.7 \%$ in placebo. ${ }^{20}$ Another double-blind RCT by Keystone et al recruited 982 patients for 52 weeks, and showed that ACR20 response rates in groups receiving $200 \mathrm{mg}$ and $400 \mathrm{mg}$ of certolizumab pegol were $58.8 \%$ and $60.8 \%$, respectively, compared with $13.6 \%$ for placebo in patients who had previously failed to respond to MTX. The trial also showed that the drug had slowed mean radiographic progression from baseline by week 52, and improved physical function as early as week $1 .^{21}$

Recently, the FAST4WARD study demonstrated the efficacy and safety of $400 \mathrm{mg}$ certolizumab monotherapy given every 4 weeks, in 220 patients previously failing $\geq 1$ DMARD therapy. The ACR20 response rate achieved after 24 weeks was $45.5 \%$ in certolizumab group as compared to $9.3 \%$ in the placebo group $(P<0.001)$. Other significant outcomes achieved during the study include ACR50, DAS28(ESR)3 scores. $^{22}$
Although the efficacy profile of certolizumab appears to be at par with other TNF inhibitors, serious adverse events are not unusual, infections being the most frequent. Among the most frequent serious infectious adverse events were lower respiratory infection, gastroenteritis, urinary tract infections, and reactivation of tuberculosis. ${ }^{21}$

\section{Golimumab (Simponi ${ }^{\circledR}$ )}

Golimumab is similar in structure to infliximab except that it has been engineered to be fully human and is given in the dose of $50 \mathrm{mg}$ as once-monthly subcutaneous injection.

The efficacy of golimumab has been evaluated through phase III clinical trials in the treatment of patients with active RA despite MTX therapy. Investigators observed; the patients receiving $100 \mathrm{mg}$ golimumab + MTX or $50 \mathrm{mg}$ golimumab + MTX achieved 56.2\% and 55.1\% ACR20 response rates, respectively as compared to $44.4 \%$ in patients receiving $100 \mathrm{mg}$ golimumab plus placebo. ${ }^{23}$ The addition of golimumab to MTX significantly reduced the signs and symptoms of RA and improved physical function.

The efficacy of golimumab plus MTX was confirmed in a multicenter, double-blind, placebo-controlled, dose-ranging RCT involving 172 patients who were randomly assigned to receive placebo plus MTX or $50 \mathrm{mg}$ or $100 \mathrm{mg}$ golimumab every 2 or 4 weeks plus MTX through week 48. At week $16,61 \%$ of patients in the combined golimumab plus MTX groups achieved ACR20 response as compared to 37\% of patients in the placebo plus MTX group $(P=0.010)$ and 79\% of patients in the group receiving $100 \mathrm{mg}$ golimumab every 2 weeks achieved ACR20 response $(P=0.001) .{ }^{24}$

Findings from 2 phase III clinical trials presented at the EULAR Annual Conference of Rheumatology provide data for the efficacy of golimumab in RA. The GO-AFTER trial evaluated the efficacy of golimumab in 461 patients with active RA, who were previously treated with TNF inhibitors,

Table I TNF- $\alpha$ inhibitors in rheumatoid arthritis (RA)

\begin{tabular}{|c|c|c|c|c|c|}
\hline & \multicolumn{3}{|l|}{ First generation } & \multicolumn{2}{|l|}{ Newly approved } \\
\hline & Infliximab & Etanercept & Adalimumab & Certolizumab & Golimumab \\
\hline Structure & Mouse-human chimeric mab & $\begin{array}{l}\text { TNF- } \alpha \text { receptor lgG } \\
\text { fusion protein }\end{array}$ & Fully human mab & $\begin{array}{l}\text { PEGylated Fc-free } \\
\text { Fab' mab }\end{array}$ & Fully human mab \\
\hline Dose & iv, 3-10 mg/kg q 4-8 weeks & sc, 50 mg weekly & sc, $40 \mathrm{mg}$ q/o week & sc, 400 mg q 2 weeks & sc, $50 \mathrm{mg} \mathrm{q} 4$ weeks \\
\hline Half life & 10 days & 3 days & I4 days & 14 days & $?$ \\
\hline Side effects & a & a & a & a & a \\
\hline $\begin{array}{l}\text { Stage of RA } \\
\text { (early/late) }\end{array}$ & Both & Both & Both & Late RA & Late RA \\
\hline
\end{tabular}

${ }^{a}$ Combined side effects of TNF- $\alpha$ inhibitors include serious infections, opportunistic/invasive fungal infections, skin cancer, congestive heart failure, demyelination, HepB reactivation, lupus-like syndrome.

Abbreviations: iv, intravenous; sc, subcutaneous; q, every; q/o, every other. 
but where TNF inhibitors were discontinued due to lack of efficacy, intolerance or other reasons. At week 14, 35\% and $38 \%$ of patients receiving $50 \mathrm{mg}$ and $100 \mathrm{mg}$ golimumab, respectively, achieved the primary endpoint of ACR 20 improvement compared with $18 \%$ of patients receiving placebo $(P<0.001)$. At week $24,52 \%$ of golimumab-treated patients experienced clinically relevant improvement (increase in HAQ score of at least 0.25 from baseline) compared with $34 \%$ of placebo-treated patients $(P<0.001)$. Also at week 24 , patients receiving golimumab experienced a mean improvement in HAQ of $0.27 \pm 0.51$, compared with an improvement of $0.05 \pm 0.51$ among patients receiving placebo $(P<0.001)$. Importantly, among patients whose prior anti-TNF therapy was discontinued due to lack of efficacy, golimumab-treated patients experienced a mean improvement of $0.23 \pm 0.50$ in HAQ, compared with an average improvement of $0.06 \pm 0.51$ for patients receiving placebo $(P<0.05){ }^{25}$

In the GO-FORWARD trial, involving 444 patients, $50 \mathrm{mg}$ and $100 \mathrm{mg}$ monthly doses of golimumab were evaluated in patients who had active RA and were previously treated with MTX. Patients in the active treatment group achieved higher ACR 20 response at week 14 and significantly higher improvement of physical function at week 24 (HAQ $0.46 \pm 0.53$ vs $0.13 \pm 0.58[P<0.001]){ }^{25}$

The combination of golimumab and MTX appears to be generally well tolerated, with most adverse events ranging mild to moderate in severity. The most common adverse effects of golimumab therapy include nausea, headache and injection site reactions. Pneumonia was the most common serious adverse event observed in the patients receiving golimumab. Skin malignancy risk is elevated in golimumabtreated patients, as is with other TNF inhibitors. ${ }^{24}$

The current data show that treatment with golimumab may induce an important depth of response, improving multiple aspects of RA and leading to significant decreases in disease activity. However, the efficacy of golimumab has not been tested against other TNF inhibitors in the existing studies. Thus, the appeal of golimumab in an already crowded arena will probably be as a self-injectable, fully humanized molecule given monthly. Notably, the currently approved dose in the US is $50 \mathrm{mg}$ and, therefore, efficacy and safety data extrapolated from the clinical trials should correspond to this particular dose.

\section{Safety and tolerability of TNF inhibitors}

TNF inhibitors have been indicated for the treatment of RA for more than 10 years and, as a result, they have a well established safety profile.
There is growing evidence that TNF inhibition is associated with serious infections, and clearly an impairment of host defense mechanism to fight gram-positive, gramnegative bacteria, and less common pathogens causing opportunistic infections. Of particular concern are multiple reports of reactivation of Mycobacterium tuberculosis latent infections. Serious bacterial infections have been reported, including 2 fatal cases of pneumococcal sepsis and necrotizing fasciitis, and multiple cases of listeriosis (mostly with infliximab therapy). ${ }^{10}$

A number of studies have attempted to determine the incidence of tuberculosis in RA. As investigated in Korean population, the risk of tuberculosis was 8.9-fold higher for patients with RA and 30.1-fold higher for patients with RA treated with infliximab; etanercept use was not associated with any increased risk of tuberculosis above that seen in the general RA population. ${ }^{26}$ In lieu of these safety concerns, many experts recommend vigilant monitoring for the development of tuberculosis while on anti-TNF therapy and preventive measures. Evidence for an increased risk for serious infections and a dose dependent increase in malignancies was identified in systematic review and meta-analysis of nine randomized controlled trials of infliximab and adalimumab in patients with RA. ${ }^{27}$ Reports have also shown an increased mortality rate in RA patients with congestive heart failure NYHA III/IV treated with TNF inhibitors (especially infliximab). ${ }^{10,28}$

Evidence of invasive fungal infections (IFIs) also exists in association with the use of TNF inhibitors. As reported by Tsiodras et al, $80 \%$ of cases of IFIs were associated with infliximab, $16 \%$ with etanercept, and $4 \%$ with adalimumab; and the most prevalent IFIs identified were histoplasmosis $(30 \%)$, candidiasis $(23 \%)$, and aspergillosis $(23 \%) .{ }^{29}$ The increased susceptibility to IFIs was thought to be attributed to the inhibition of IFN- $\gamma$ production, decreased expression of pattern-recognition receptors, and leukocyte apoptosis. ${ }^{30}$ Therefore a high index of suspicion and increased surveillance of IFIs complicating TNF blockade is recommended because the course of such infections can be serious or fulminant, and rapid access to health care should be provided.

Recently Carter et al evaluated the safety profile of TNF inhibitors in pregnancy. ${ }^{31}$ Their report suggested that $59 \%$ of children born to mothers taking TNF inhibitors had one or more congenital anomalies that are part of vertebral abnormalities, anal atresia, cardiac defect, tracheoesophageal, renal, and limp abnormalities (VACTERL) association and the most common reported congenital anomaly was some form of heart defect. However, in an abstract presented at the 
2008 ACR scientific meeting, none of the fetuses exposed to infliximab in utero presented with VATER (VACTERL) malformations. ${ }^{32}$

Similarly, in another two 2008 ACR presentations on the pregnancy outcomes in women exposed to adalimumab (119 women) and etanercept (154 women) respectively, no concerns were raised regarding increased risks for specific pregnancy related outcomes. ${ }^{33,34}$

Ongoing registries, such as the one kept by the Organization of Teratology Information Specialists (OTIS), will be able to address the issue of safety in pregnancy more definitively in the near future. Certolizumab, one of the newer biologics, has the theoretical advantage of lacking an Fc portion, which is necessary for transport through the placenta, and it remains to be proven whether it may be safer for women trying to conceive.

TNF inhibitors have also been associated with the development of autoimmune diseases like systemic lupus erythematosis, lupus-like syndrome, cutaneous vasculitis, interstitial lung disease, and Behcet's disease. ${ }^{35,36}$ Possible mechanisms that may induce antibody-production by TNF- $\alpha$ inhibitors include dysregulation of apoptosis with release of autoimmungenic plasma nucleosomes from apoptotic cells that trigger formation of autoantibodies against cytoplasmic and nuclear compounds or inhibition of a cytotoxic T lymphocyte response that normally suppresses autoreactive B cells. ${ }^{37}$ However, greater concentrations and frequencies of antinuclear, anticardiolipin and anti-dsDNA antibodies described with infliximab compared with etanercept or adalimumab suggest that factors other than TNF blockade may be responsible for induction of these autoimmune diseases. ${ }^{38,39}$

Because there may be a class effect, patients who fail treatment with a TNF inhibitor because of a tolerability or safety issue may be at increased risk for a similar safety problem on an alternative TNF inhibitor. A UK-based study reported; the reasons for discontinuation of the switch-over (second) antiTNF- $\alpha$ agent were related to the reasons for stopping the first anti-TNF- $\alpha$ agent. Furthermore, the risk for developing an adverse event with a second TNF inhibitor increased 2-fold in patients switched because of an adverse event. ${ }^{40}$

\section{Interleukin-I receptor blocker}

\section{Anakinra $\left(\right.$ Kineret $\left.^{\circledR}\right)$}

Anakinra is recombinant, non-glycosylated form of IL-1 receptor antagonist with half life of 4 to 6 hours and is administered as $100 \mathrm{mg}$ subcutaneous daily injection. Presently, anakinra is the only IL-1 antagonist marketed and approved for the treatment of RA, alone or in combination with MTX.
Table 2 Interleukin-I (IL-I) receptor blockers in rheumatoid arthritis (RA)

\begin{tabular}{lll}
\hline & Anakinra & AMG I08 \\
\hline Structure & Recombinant, non-glycosylated form of & - \\
& IL-I receptor antagonist & \\
Dose & sc, $100 \mathrm{mg}$ daily & - \\
Half-life & 4-6 hours & - \\
Side effects & Injection site reactions, Serious infections & - \\
Stage of RA & Late RA & - \\
(early/late) & & \\
\hline
\end{tabular}

Abbreviation: sc, subcutaneous.

In Europe, this agent has been approved for the treatment of RA only in combination with MTX.

The efficacy of anakinra was evaluated as an add-on therapy in RA patients with inadequate response to monotherapy with non-biological DMARDS. Anakinra (100 mg, daily sc) was administered along with topical corticosteroid cream, despite patients on MTX $(n=48)$, leflunomide $(n=42)$, or cyclosporine-A $(n=32)$ treatment. At 48 weeks, the percentage of patients achieving ACR20, ACR50, and ACR70 responses were $73 \%, 41 \%$, and $23 \%$ respectively. ${ }^{41}$ Another pooled analysis of 5 clinical trials involving 2846 patients reported significant improvement of ACR20 response in the participants treated with anakinra 50 to $150 \mathrm{mg}$ daily vs placebo after 24 weeks ( $38 \%$ vs 23\%). Significant improvements were also observed with anakinra vs placebo in the following parameters: ACR50 (18\% vs 7\%), ACR70 (7\% vs 2\%), HAQ score, visual analogue score for pain, Larsen radiographic scores, and ESR. ${ }^{42}$

Anakinra is fairly well tolerated, with injection-site reactions being the most common side effects, occurring in up to $70 \%$ of patients in dose-dependent manner. ${ }^{42-44}$ These reactions do not require treatment and can diminish with continued use. An increased incidence of serious infections was also noticed in anakinra treated patients, and the agent should be discontinued in the face of an active infection. ${ }^{45}$

The drug has been successfully used for many autoinflammatory syndromes. ${ }^{46}$ However, the use of anakinra for the treatment of RA has been limited worldwide due to its modest efficacy, especially when compared with the TNF inhibitors and the newer biologics. Although head-to-head comparison trials have not been carried out, the absolute improvement was less pronounced when compared to studies using other biological therapies. However, the recent development of long-acting IL-1 inhibitors (rilonacept, canakinumab) for the auto-inflammatory syndromes, may provide us with new tools, if appropriate trials are ever conducted, to answer 
the question whether the lack of efficacy of anakinra lies within its mechanism of action (IL-1 inhibition) vs specific attributes of the molecule, especially its pharmacokinetic properties.

\section{Interleukin-6 receptor blocker Tocilizumab (Actemra ${ }^{\circledR}$ )}

Tocilizumab, a new humanized, antihuman IL-6 receptor antibody with a number of randomized controlled trials evaluating its efficacy in RA, is now approved for the treatment of RA in Japan. ${ }^{47}$ Elevated levels of IL-6 in the serum and synovial fluid of RA patients contribute to the chronic inflammatory process characterizing RA and correlate positively with disease activity. Tocilizumab binds selectively and competitively to soluble and membraneexpressed IL-6 receptors, blocking IL-6 signal transduction. ${ }^{48}$ A number of trials in patients with early or long standing RA, have demonstrated the efficacy of intravenous tocilizumab $8 \mathrm{mg} / \mathrm{kg}$ every 4 weeks in improving disease activity, structural joint damage and/or HRQoL. ${ }^{49}$

Tocilizumab as monotherapy has shown efficacy in patients with an inadequate response to MTX therapy. ${ }^{50,51}$ The AMBITION study randomized 673 patients with active RA to receive either tocilizumab or MTX for a period of 24 weeks. Results demonstrated statistically significant improvement of the primary endpoint (ACR20) in patients treated with tocilizumab compared to MTX treatment (69.9\% vs 52.5\%, $P<0.0001) .{ }^{50}$ The SATORI (Study of Active controlled TOcilizumab monotherapy for RA patients with an Inadequate response to MTX) study also demonstrated superior efficacy among $80.3 \%$ of patients treated with $8 \mathrm{mg} / \mathrm{kg}$ of tocilizumab monotherapy every 4 weeks, achieving the primary endpoint (ACR20) at 24 weeks in comparison to $25 \%$ patients treated with $8 \mathrm{mg} /$ week MTX therapy. ${ }^{51}$

Table 3 IL-6 receptor blocker (tocilizumab) in rheumatoid arthritis (RA) ${ }^{\mathrm{a}}$

\begin{tabular}{ll}
\hline Structure & Humanized anti-human IL-6 receptor Ab \\
Dose & iv, $4-8 \mathrm{mg} / \mathrm{kg}$ body weight q 4 weeks \\
Half life & $1.8-11.4$ days at $4 \mathrm{mg} / \mathrm{kg} ; 3.8-12.9$ days at $8 \mathrm{mg} / \mathrm{kg}$ \\
Side effects & $\begin{array}{l}\text { Mild-moderate infections, hypertension, neutropenia, } \\
\text { thrombocytopenia, hypercholesterolemia, AST/ALT } \\
\text { elevation }\end{array}$ \\
Stage of RA & Early and late RA \\
(early/late) &
\end{tabular}

${ }^{a}$ Tocilizumab has been approved for treatment of RA in Japan.

Abbreviations: IL, interleukin; iv, intravenous; q, every.
The combination therapy of tocilizumab plus MTX was found to be more efficacious than tocilizumab monotherapy by various investigators. In a European study, researchers observed ACR20 response in 74\% of patients receiving combination of $8 \mathrm{mg} / \mathrm{kg}$ tocilizumab plus MTX in comparison to $63 \%$ in patients receiving $8 \mathrm{mg} / \mathrm{kg}$ tocilizumab monotherapy. Additionally, statistically significant ACR50 and ACR70 responses $(\mathrm{P}<0.05)$ were found in patients receiving the combination therapy. ${ }^{52}$

A study conducted by Emery et al demonstrated convincingly efficacy of tocilizumab plus MTX in RA patients with inadequate response to TNF inhibitors, a growing subpopulation of RA patients. ${ }^{53}$

As of safety profile, tocilizumab was well tolerated by adult patients with early and long-standing RA. Most frequently reported treatment-emergent adverse effects were mild to moderate in intensity, included upper respiratory tract infections, nasopharyngitis, headache, hypertension, and total cholesterol and ALT elevations. ${ }^{49}$ However, recently a study also identified marked suppression in the number of neutrophils in the peripheral blood of RA patients 1 day after the administration of tocilizumab, which may predispose to the development of infections, by adding an additional risk factor to an already underlying immunosuppressed state. ${ }^{54}$ Further studies are being conducted to better define the safety profile of this agent.

In conclusion, intravenous tocilizumab is effective and generally well tolerated when administered either as monotherapy or in combination with conventional DMARDs in adult patients with moderate to severe active RA, regardless of disease duration or prior therapy.

\section{B-cell depletion therapy Rituximab $\left(\right.$ Rituxan $\left.^{\circledR}\right)$}

B-cell depletion using anti-CD20 antibodies is becoming a widely recognized therapeutic option for patients with severe RA, and currently rituximab is FDA approved in the United States for the treatment of RA in patients who have exhibited an inadequate response to or were intolerant to one or more TNF inhibitors in combination with MTX, on the basis of several randomized placebo-controlled studies. ${ }^{55-57}$

Rituximab is chimeric human/mouse anti-CD20 antibody, with plasma half life of 40 to 400 hours, and is administered in dose of two $1000 \mathrm{mg}$ intravenous infusions separated by 2 weeks. Rituximab induces a rapid depletion of normal CD20-expressing B-cells in the peripheral blood, and levels remain low or undetectable for 2 to 6 months before returning to pretreatment levels, generally within 12 months. 
Table 4 B-cell depleting agents (anti-CD20) in rheumatoid arthritis (RA)

\begin{tabular}{|c|c|c|c|c|}
\hline & \multirow{2}{*}{$\frac{\text { Currently used }}{\text { Rituximab }}$} & \multicolumn{3}{|l|}{ In development } \\
\hline & & Ocrelizumab & Ofatumumab & TRU-0I5 \\
\hline Structure & $\begin{array}{l}\text { Chimeric human/mouse CD20 } \\
\text { agonist }\end{array}$ & $\begin{array}{l}\text { Humanized (90\%) CD20 } \\
\text { agonist }\end{array}$ & $\begin{array}{l}\text { Fully human CD20 agonist } \\
\text { (HuMax-CD20) }\end{array}$ & $\begin{array}{l}\text { Human CD20 agonist with } \\
\text { smaller mol structure }\end{array}$ \\
\hline Dose & $\begin{array}{l}\text { iv, two } 1000 \mathrm{mg} \text { infusion separated } \\
\text { by } 2 \text { weeks }\end{array}$ & $\begin{array}{l}\text { iv, two } 200 \mathrm{mg} \text { infusions } \\
\text { separated by } 2 \text { weeks }\end{array}$ & - & - \\
\hline Half-life & $40-400$ hours & - & - & - \\
\hline Side effects & $\begin{array}{l}\text { Infusion reactions, infection risk, } \\
\text { IGM decline, immunization }\end{array}$ & Infusion reactions & - & - \\
\hline $\begin{array}{l}\text { Stage of RA } \\
\text { (early/late) }\end{array}$ & Late RA & - & - & - \\
\hline
\end{tabular}

Abbreviations: IgM, immunoglobulin M; iv, intravenous.

Serum immunoglobulin levels remain largely stable, although a reduction in IgM has been described.

The Randomised Evaluation oF Long-term Efficacy of rituXimab in RA (REFLEX) phase 3 study on 517 RA patients showed that rituximab plus MTX treatment significantly reduced joint damage progression compared with placebo plus MTX. Significant reductions were observed from baseline to 56 weeks for rituximab plus MTX compared with placebo plus MTX in the following measures: Genant modified Sharp score (1.00 vs 2.31 in placebo; $P=0.005)$, erosion score $(0.59$ versus 1.32 ; $P=0.011)$ and joint space narrowing score ( 0.41 vs 0.99 ; $P<0.001) .{ }^{58}$ This difference is remarkable, given that the majority of patients in the placebo group (81\%) received at least one course of rituximab, because from weeks 16 to 24 patients who had failed to respond to treatment $(<20 \%$ improvement in swollen joint counts) could receive rescue therapy. In addition, rituximab has been shown to inhibit the radiographic progression independent of clinical response in such patient population. ${ }^{1}$

Results of an observational study in a population of patients with inadequate response to one or more TNF inhibitors indicated that rituximab may be more effective at controlling disease activity than switching to an alternative TNF inhibitor. Significant decrease in DAS 28 was reported in patients treated with rituximab $(-1.61,95 \% \mathrm{CI}=-1.97$ to -1.25$)$ than in those treated with an alternative TNF inhibitor $(-0.98,95 \% \mathrm{CI}=-1.33$ to -0.62$)$ after 6 months of therapy. ${ }^{59}$ However, when the motive for interrupting TNF- $\alpha$ therapy was something other than ineffectiveness, both rituximab and alternative TNF- $\alpha$ agents appear to offer similar levels of effectiveness, as shown in previous studies. ${ }^{40}$

Rituximab is by far the only agent that has formally demonstrated significant slowing of structural joint damage in RA patients with an inadequate response to or who are intolerant to TNF inhibitors. Although well known for its efficacy, rituximab can result in serious, including fatal infusion reactions, and rare progressive multifocal leukoencephalopathy (PML). PML has been well reported infectious complication occurring in patients with systemic lupus erythematosus (SLE). As reported by Molloy et al, nearly two thirds of cases of PML in patients with rheumatic diseases reported in the medical literature occurred in SLE patients. ${ }^{60}$ Twenty-three rituximab-treated oncology patients were reported by the FDA to have developed PML as of December 6, 2007. Most of these patients received rituximab in combination with chemotherapy or stem cell transplantation. ${ }^{61}$ However the occurrence of PML in RA patients has not been reported till date. Although the risk due to rituximab is difficult to assess given the multiple confounders, continued vigilance is warranted. Therefore the rheumatologists need to be vigilant and pursue the diagnosis of PML in all patients with unexplained neurological signs or symptoms with clinical and MRI findings compatible with the diagnosis. Once established, rituximab therapy should be discontinued; dose reductions and discontinuation should be considered for any concomitantly administered immunosuppressants. Additional concern that remains unaddressed is the number of rituximab infusions that can be safely administered.

\section{Ocrelizumab}

Ocrelizumab (OCR) is a novel anti-CD20 humanized monoclonal antibody, currently in clinical trials for the treatment of RA. In comparison with rituximab, ocrelizumab binds to a different, but overlapping, epitope of the extracellular domain of CD20 receptor. In vitro characterization of ocrelizumab demonstrated enhanced ADCC and reduced CDC compared with rituximab. ${ }^{62}$ 
The ACTION trial (a randomized, placebo-controlled, blinded, phase I/II study of escalating doses of ocrelizumab in patients with moderate to severe RA on stable doses of concomitant MTX) investigated ocrelizumab across a wide range of doses in patients with moderate to severe RA receiving concomitant MTX therapy ${ }^{62}$ A single course of ocrelizumab ( 2 infusions on days 1 and 15) at doses ranging from 10 to $1000 \mathrm{mg}$ was administered. Clinical response was evaluated at 24 weeks and safety profile at 72 weeks of follow-up. A higher proportion of patients in all of the ocrelizumab groups achieved an ACR20, ACR50, or ACR70 response at week 24 as compared with patients in the placebo group. The ACR20 response rates at week 24 were $42 \%, 35 \%, 45 \%$ and $50 \%$ in those receiving $10 \mathrm{mg}$, $50 \mathrm{mg}, 200 \mathrm{mg}$, and 500/1000 mg of OCR respectively. The ACR20 response rate in the placebo group was $22 \%$.

The safety profile of ocrelizumab in this study was consistent across dosing groups and suggested only slight differences compared with placebo. The incidence of serious adverse events in the ocrelizumab-treated patients was 17.9\% as compared with $14.6 \%$ in placebo group. The incidence of serious infections was $2.0 \%$ in all ocrelizumab treated patients and $4.9 \%$ in placebo-treated patients. All serious infections that were observed, resolved without sequelae.

Although ocrelizumab was well tolerated and appeared to be safe, additional experience with multiple trials will be required to validate the outcomes and further understand the clinical significance of human anti-human antibodies and potential advantages of this therapeutic approach over treatment with chimeric antibodies.

\section{T-cell targeted therapy Abatacept (Orencia ${ }^{\circledR}$ )}

Abatacept is a fusion protein consisting of the human cytotoxic T-lymphocyte-associated antigen-4 molecule (CTLA-4) and immunoglobulin G1, both of which occur naturally in the body. By mimicking the actions of CTLA-4, abatacept inhibits one of the key costimulatory pathways (CD28:CD80/CD86) required for full T-cell activation. ${ }^{63}$ The drug has been approved for the treatment of RA patients who have exhibited an inadequate response to or were intolerant of one or more DMARDs or TNF inhibitors in the USA, or one or more TNF inhibitors only in Europe. ${ }^{1}$ Abatacept may be used either as a monotherapy or concomitantly only with DMARDs. As reported in the ASSURE (Abatacept Study of Safety in Use with other Rheumatoid arthritis therapies) trial, abatacept in combination with biologic background therapies was associated with an increased rate of serious
Table 5 T-cell costimulation (abatacept)in rheumatoid arthritis (RA)

$\begin{array}{ll}\text { Structure } & \begin{array}{l}\text { Soluble fusion protein consisting of the extracellular } \\ \text { domain of human CTLA4 and a fragment of the Fc } \\ \text { portion of human IgGI (hinge and CH2 and } 3 \text { domains) }\end{array} \\ \text { Dose } & \begin{array}{l}\text { iv dose according to body weight (approximately } \\ 10 \mathrm{mg} / \mathrm{kg}):<60 \mathrm{~kg}: 500 \mathrm{mg}, 60-100 \mathrm{~kg}: 750 \mathrm{mg}, \\ >100 \mathrm{~kg}: 1000 \mathrm{mg}\end{array} \\ \text { Half life } & \text { I3 days } \\ \text { Side effects } & \text { Headache, increased infection risk, COPD exacerbation } \\ \text { Stage of RA } & \text { Early and Late RA } \\ \text { (early/late) } & \end{array}$

Abbreviations: COPD, chronic obstructive pulmonary disease; Fc, crystallizable fragment; iv, intravenous.

adverse events. ${ }^{64}$ Therefore, abatacept is contra-indicated for concomitant use with TNF- $\alpha$ inhibitors, anakinra, and/or other biological therapies.

Several phase III trials have shown abatacept to be an effective option in patients who are refractory to TNF- $\alpha$ inhibition with impressive quality of life improvements. Two clinical trials evaluated the efficacy of abatacept for difficult-to-treat patients: the AIM for MTX-resistant cases and the ATTAIN for patients who are resistant to TNF- $\alpha$ inhibitors. ${ }^{65,66}$

A more recent randomized, double-blind placebo- and active (infliximab)-controlled, 12-month global trial known as ATTEST (for Abatacept or infliximab vs placebo, a Trial for Tolerability, Efficacy and Safety in Treating rheumatoid arthritis) suggested that standard weight-based abatacept might have comparable efficacy with a more favorable safety profile than infliximab $3 \mathrm{mg} / \mathrm{kg} .{ }^{67}$ Trial was designed to obtain data on the magnitude of the treatment effect in RA of abatacept or infliximab (an established inhibitor of TNF for RA) vs placebo, and to obtain relative efficacy and safety data on these two biological treatments in a single study. The study utilized a double-blind, randomized, placebo-controlled design for the first 6 months to validate efficacy responses, and the study duration allowed for the opportunity to directly compare the safety profile of the active biologic treatment groups over 1 year. ${ }^{67}$

In this study, abatacept and infliximab $(3 \mathrm{mg} / \mathrm{kg}$ every 8 weeks) demonstrated similar efficacy. But overall, abatacept had a relatively more acceptable safety and tolerability profile, with fewer serious adverse events, serious infections, acute infusional events and discontinuations due to adverse events than the infliximab group. Limitations of the study were its short duration and the fact that the comparator (infliximab) dose was $3 \mathrm{mg} / \mathrm{kg}$, the only approved dose at the time in the European Union. 
The efficacy of combined therapy, abatacept plus MTX have been confirmed by a 2 -year follow-up study, where $80.3 \%$ of patients taking abatacept showed ACR20 improvement, $30.9 \%$ achieved remission (CRP-DAS28 < 2.6) and 66.8\% enhanced their physical function (as measured by the HAQ disability index). The mean changes in the physical and mental components summary scores of the Short-Form-36 also confirmed a good improvement of HRQoL. ${ }^{68}$

The efficacy and safety of abatacept has also been evaluated in RA patients receiving etanercept. However, the percentage improvements in ACR20 response after 6 months of abatacept therapy were disappointing. Furthermore, after 1 year of association of these two biologics, no notable changes in ACR responses were observed. ${ }^{69}$ Moreover this combination was shown to be linked to an increase in serious adverse events rate compared with patients receiving placebo and etanercept (16.5 vs $2.8 \%$ ).

Unlike previous clinical trials enrolling patients with long-standing RA, Westhovens et al recently evaluated the efficacy of abatacept in MTX-naïve patients with early RA. ${ }^{70}$ Abatacept study to Gauge Remission and joint damage progression in MTX-naïve patients with Early Erosive RA (AGREE) was a 2-year, double-blind trial that enrolled patients with less than 2 years of disease without MTX exposure ( $\leq 10 \mathrm{mg} /$ week for $\leq 3$ ). The study population of 509 patients was randomized to receive placebo plus MTX (increased up to $20 \mathrm{mg} /$ week) or abatacept $10 \mathrm{mg} / \mathrm{kg}$ plus MTX for 12-months before an open-label 12 month extension. The co-primary endpoints of the study were remission (DAS28 < 2.6) and Genant-modified Sharp total score. At year 1, 41.4\% of abatacept-treated patients achieved remission as compared to $23.3 \%$ patients of placebo group. The proportion of patients with no radiographic progression was $61.2 \%$ and $52.9 \%$ in the abatacept and placebo-treated patients, respectively (difference of $8.3,95 \% \mathrm{CI}-1.0,17.5)$. The change from baseline in total Genant-modified Sharp scores and erosion scores were significantly lower for abatacept, while minimal joint space narrowing progression was noted in both groups. Furthermore, $71.9 \%$ of abatacept-treated patients had clinically important improvement in the HAQ-DI compared to $62.1 \%$ in the placebo group $(P=0.024)$.

The safety profile of abatacept is comparable to that of other biologics. Severe infections were more common in abatacept-treated patients than in placebo-treated patients. ${ }^{71}$ Opportunistic infections are rare in patients with abatacept and the frequency of malignancies, based on post-marketing surveillance and international patient cohorts, is not higher than expected in RA patients treated with DMARDS. ${ }^{72}$

\section{Upcoming biological targets and therapies}

Since substantial cross-talk between pro-inflammatory cytokines IL- $1 \beta$, TNF- $\alpha$, IL- 6 , and IL-17 is essential to induce joint destruction in RA, ${ }^{1} \mathrm{IL}-1 \beta$ and TNF- $\alpha$ promote IL-6 and tumor growth factor-beta (TGF- $\beta$ ) driven process of Th17 cell commitment and IL-17 production. ${ }^{73}$ Th17 cell polarization further induces IL- $1 \beta$, TNF- $\alpha$, IL-6, IL-8, and IL-17 production (Figure 1) ${ }^{74-77}$ Numerous studies have also demonstrated the critical role of B-cells in RA pathogenesis. A range of activated leukocyte cell types produce the TNF family B-cell pro-survival factors BLys (B-Lymphocyte stimulator) or BAFF (B-cell activation factor belonging to the TNF family) and APRIL (a proliferation inducing ligand). ${ }^{78,79}$ Levels of BAFF and APRIL are elevated in RA patients, with significantly higher levels in synovial fluid than in the serum. ${ }^{80,81}$ As illustrated in Figure 1, BLyS/BAFF binds 3 receptors: BLyS receptor 3 (BR3, also termed BAFFR), transmembrane activator and calcium-signaling modulating and cyclophilin ligand (CAML) interactor (TACI), and B cell maturation antigen (BCMA) in contrast to APRIL, which selectively promote TACI and BCMA receptor-mediated NF-k $\beta$ signaling mechanisms. ${ }^{82}$

The following biological agents are being evaluated in ongoing trials (Figure 2 and Table 6):

a. B-cell agents targeting CD20 (ocrelizumab, ofatumumab, and TRU-015), agents targeting cytokines important in the later stages of B cell maturation: BLyS or BAFF (belimumab, briobacept) and APRIL (atacicept), as well as other compounds targeting intracellular kinases Jak3 (CP 690,550) and Syk.

b. T-cell agents targeting lymphotoxin beta (LT $\beta)$ and LIGHT (baminercept)

c. Cytokine targeting agents: IL-1 (AMG 108), IL-6 (tocilizumab), and IL-17A (AIN 457)

d. Agents targeting osteoclasts via RANKL inhibition (denosumab)

\section{Discussion}

The following are unanswered questions on biological therapy in RA:

1. Initiation of biologics: early or established RA?

2. Can biomarkers guide initiation of biological therapy?

3. Inter-class comparison of existing and upcoming biologics: which and when to start?

4. Need for a standard step-up/step-down therapy protocol for biologics: establishing a therapeutic algorithm for RA? 


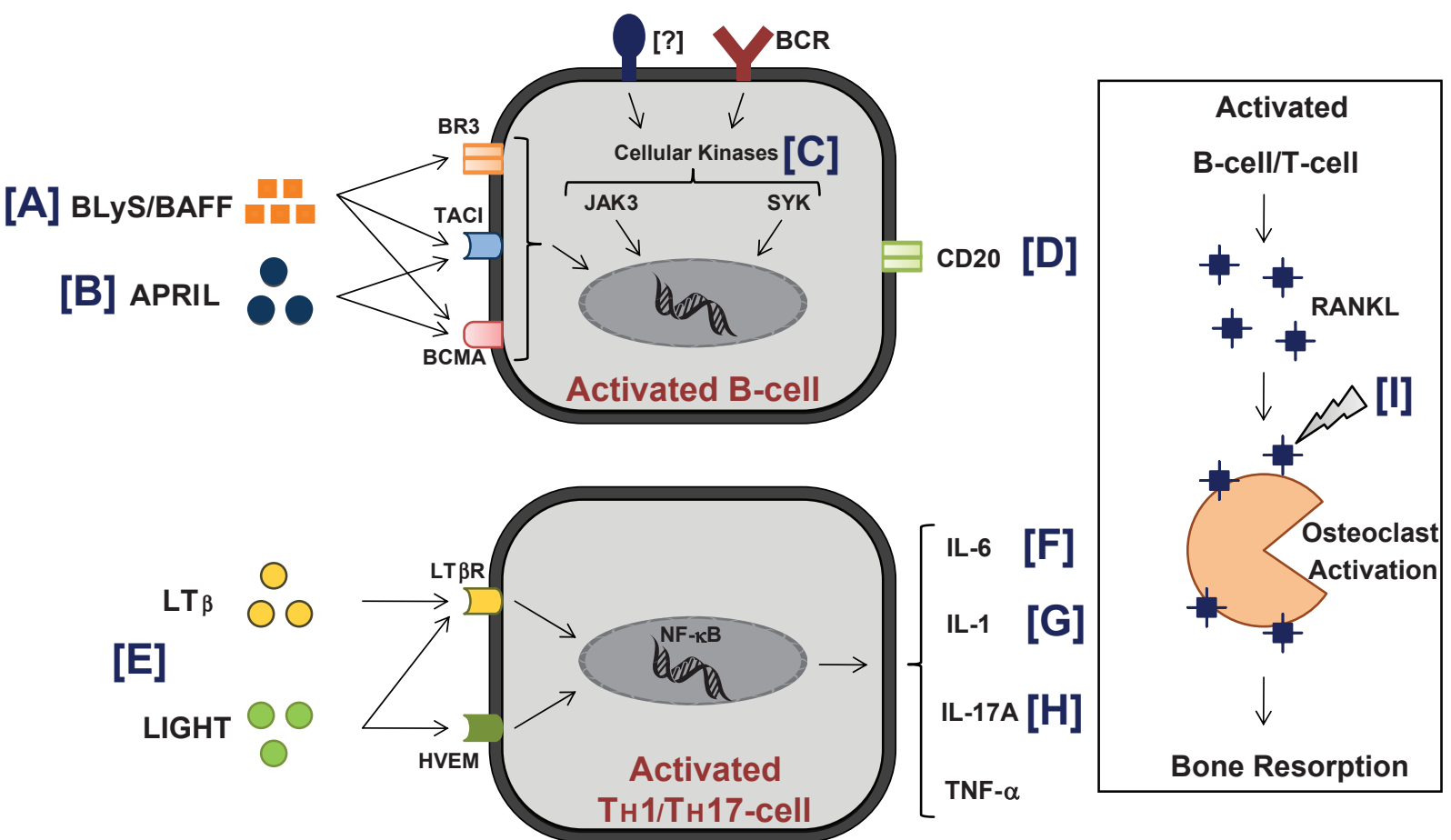

Figure I Molecular targets of drugs in clinical trials for rheumatoid arthritis

Abbreviations: APRIL, a proliferation-inducing ligand; BCR, B-cell receptor; BLyS, B-lymphocyte stimulator; BAFF, B-cell activating factor; BR3, BLyS receptor 3; BCMA, B cell maturation antigen; HVEM, herpes virus-entry mediator; IL, interleukin; LT $\beta$, lymphotoxin beta; RANKL, receptor activator of nuclear factor kappa B ligand; TACI, transmembrane activator and CAML-interactor;TNF- $\alpha$, tumor necrosis factor alpha.

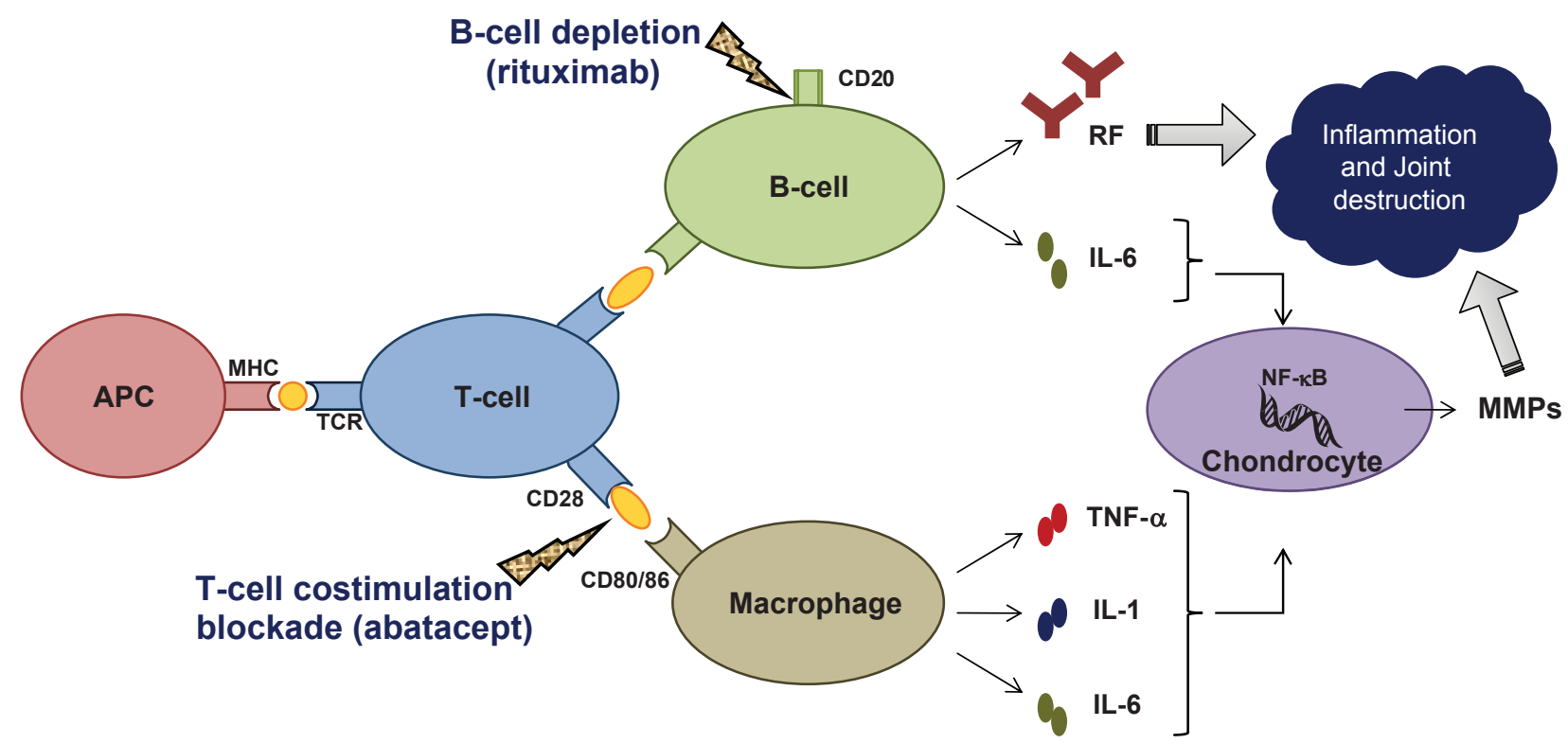

\section{$\underline{\text { Inhibitors }}$}

TNF- $\alpha$ Infliximab, etanercept, adalimumab, certolizumab, golimumab

\section{IL-1 C Anakinra}

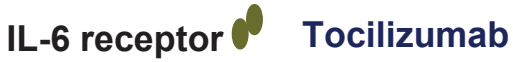

Figure 2 Inflammatory cascade and molecular targets of current biologics in rheumatoid arthritis.

Abbreviations: APC, antigen presenting cell; IL, interleukin; MHC, major histocompatibility complex; MMP, matrix metalloproteinase; NF- $\kappa \beta$, nuclear factor Kappa beta; RF, rheumatoid factor; TCR, T-cell receptor; TNF- $\alpha$, tumor necrosis factor alpha. 
Table 6 Biological agents in development for rheumatoid arthritis ${ }^{\mathrm{a}}$

\begin{tabular}{lll}
\hline Cellular targets & Biological agents & Recent trials \\
\hline I. IL-I inhibitors & AMG I08 & Completed Phase II \\
2. IL-6 inhibitors & Tocilizumab & Phase III \\
3. IL-I7A inhibitors & AIN 457 & Phase I/II \\
4. B-cell depleting agents & Ocrelizumab, & Phase II/III \\
& Ofatumumab, & Phase III \\
& TRU-0I5 & Phase II \\
5. Cytokines in B-cell maturation & & Phase II \\
a. BLyS inhibitor & Belimumab, briobacept & Phase II \\
b. APRIL inhibitor & Atacicept & Phase II/III \\
6. Jak3 inhibitors & CP 690,550 & Phase II \\
7. Syk inhibitors & Tamatinib fosdium & Phase II \\
8. RANKL inhibitors & Denosumab & Phase II \\
9. Lymphotoxin $\beta$ and LIGHT pathway inhibitors & Baminercept & Completed phase II \\
I0. P38 MAP inhibitors & VX 702 & Phase I \\
\hline
\end{tabular}

aData collected from the registries on ClinicaTrials.gov until May 26, 2009.

${ }^{\text {b}}$ Tocilizumab has been approved for treatment of RA in Japan.

Abbreviation: IL, interleukin.

5. Safety issues: Unique to an individual biologic agent or representative of a class effect?

6. Ongoing vigilance: Is there a better way to monitor and record potential side effects of biologics identified after approval?

7. Is it possible to discontinue biological therapy in patients achieving remission and, if so, when is the optimal timing?

8. Perioperative infection risks while a patient on biological therapy: what is the timing of discontinuation of treatment/procedure/reinitiation of therapy? Need to readdress for every new biologic.

- Biologics, usually in combination with traditional DMARDs such as MTX, have revolutionized the treatment of RA, producing significant improvement in clinical, radiographic and functional outcomes not seen previously. However, even with the availability of these medications, a significant proportion of patients either do not respond at all, or may respond initially and subsequently efficacy fades. Therefore, new agents, with different mechanisms of action, ie, targeting molecules involved in cellular interaction and/or signaling in immuno competent cells are being investigated through various clinical trials.

- Results from existing RCTs are difficult to compare, because they involve different patient populations, study designs, and treatment strategies. Moreover there may be specific factors involving the different mechanisms and onset of action which may further complicate the comparison of different biological agents.

- The key question of how to select the first/one particular biological agent to be given to a patient has been elegantly answered by Scott et al ${ }^{83}$ The probable deciding factors explained include patient's preference, relative efficacy, toxicity, and cost-effectiveness of different biologics. Different mechanisms of action might provide a theoretical rationale for the preference of one agent over another.

- Targeting individual cytokines is a tried and successful approach in RA. However, careful consideration must be given not only to the cytokine targeted but also to the stage of the disease process being targeted. Furthermore, there is a lack of data, both on efficacy and safety, about the applicability of multiple cytokine inhibition.

- Despite their clinical promises, monoclonal antibodies are raising concern about the potential adverse effects of long-term use. Published data currently do not exclude clinically important increased risks, nor do they refute beneficial effects. As per definition, much of the currently available safety data from trials or clinical practice do not capture the impact of any effects from sustained exposure to biologics. Additional studies are warranted to understand whether all these safety issues are unique to an individual biologic agent or representative of a class effect. Therefore, the treating physician must carefully weigh the benefits of these new biologics against their risks, particularly in frail patients at risk for infection. 
- Although biologics have undisputed benefits in the treatment of RA, the cost issue remains unsolved. Costs are dramatically higher than for conventional medications, pharmacoeconomic concerns have been brought in the spotlight with their ever-expanding use. Across the board, the estimated yearly cost to use a biological agent is about US $\$ 20,000$. The significant cost has to be balanced against the detrimental economic impact of RA on the individual patient and society as a whole. If biologics can prevent the morbidity, disability, and deterioration of the quality of life that RA often causes, then the use of a biological agent can be a cost-effective decision for societies. The development of biosimilar biologics, ie, generic medications that replicate the exact aminoacid structure of existing biologic DMARD molecules that lose their patent protection, may soon alter the landscape of biologics and its associated costs. However, biologics require a sophisticated manufacturing process, different from existing conventional medications and tight regulation will be required to avoid possibly additional safety risks and make these agents truly cost-effective.

- Several new therapies, currently in the pipeline, may soon be added to our already expanded number of treatment options. Different types of RA patients will require different therapies, especially those who have failed multiple agents. These new options look promising in filling gaps in the treatment of RA patients. Comparative studies in sufficient numbers of patients should help shed more light on their exact role in RA treatment.

\section{Disclosures}

PE has received consulting and/or speakers' fees from Bristol-Myers Squibb, Wyeth, and Centocor.

\section{References}

1. Rubbert-Roth A, Finckh A. Treatment options in patients with rheumatoid arthritis failing initial TNF inhibitor therapy: a critical review. Arthritis Res Ther. 2009;11 Suppl 1:S1.

2. Saklatvala J. Tumour necrosis factor alpha stimulates resorption and inhibits synthesis of proteoglycan in cartilage. Nature. 1986 Aug 7-13; 322(6079):547-549.

3. Taylor PC. Anti-TNF therapy for rheumatoid arthritis and other inflammatory diseases. Mol Biotechnol. 2001 Oct;19(2):153-168.

4. Smolen JS, Van Der Heijde DM, St Clair EW, et al. Predictors of joint damage in patients with early rheumatoid arthritis treated with high-dose methotrexate with or without concomitant infliximab: results from the ASPIRE trial. Arthritis Rheum. 2006;54(3):702-710.

5. Breedveld FC, Emery P, Keystone E, et al. Infliximab in active early rheumatoid arthritis. Ann Rheum Dis. 2004;63(2):149-155.

6. Allaart CF, Goekoop-Ruiterman YP, de Vries-Bouwstra JK, Breedveld FC, Dijkmans BA. Aiming at low disease activity in rheumatoid arthritis with initial combination therapy or initial monotherapy strategies: the BeSt study. Clin Exp Rheumatol. 2006;24(6 Suppl 43):S77-S82.
7. Quinn MA, Conaghan PG, O'Connor PJ, et al. Very early treatment with infliximab in addition to methotrexate in early, poor-prognosis rheumatoid arthritis reduces magnetic resonance imaging evidence of synovitis and damage, with sustained benefit after infliximab withdrawal: results from a twelve-month randomized, double-blind, placebo-controlled trial. Arthritis Rheum. 2005;52(1):27-35.

8. Haugeberg G, Conaghan PG, Quinn M, Emery P. Bone loss in active early rheumatoid arthritis patients treated with infliximab and methotrexate compared with methotrexate treatment alone. Explorative analysis from a twelve-month randomized, double blind, placebo-controlled study. Ann Rheum Dis. 2009. Apr 21. [Epub ahead of print].

9. Dobrzanski MJ, Reome JB, Hollenbaugh JA, Hylind JC, Dutton RW. Effector cell-derived lymphotoxin alpha and Fas ligand, but not perforin, promote Tc1 and Tc2 effector cell-mediated tumor therapy in established pulmonary metastases. Cancer Res. 2004;64(1):406-414.

10. Efthimiou P, Markenson JA. Role of biological agents in immunemediated inflammatory diseases. South Med J. 2005;98(2):192-204.

11. Moreland LW, Baumgartner SW, Schiff MH, et al. Treatment of rheumatoid arthritis with a recombinant human tumor necrosis factor receptor (p75)-Fc fusion protein. N Engl J Med. 1997;337(3):141-147.

12. Moreland LW, Schiff MH, Baumgartner SW, et al. Etanercept therapy in rheumatoid arthritis. A randomized, controlled trial. Ann Intern Med. 1999;130(6):478-486.

13. Emery P, Breedveld FC, Hall S, et al. Comparison of methotrexate monotherapy with a combination of methotrexate and etanercept in active, early, moderate to severe rheumatoid arthritis (COMET): a randomised, double-blind, parallel treatment trial. Lancet. 2008; 372(9636):375-382.

14. Klareskog L, van der Heijde D, de Jager JP, et al. Therapeutic effect of the combination of etanercept and methotrexate compared with each treatment alone in patients with rheumatoid arthritis: double-blind randomised controlled trial. Lancet. 2004;363(9410):675-681.

15. Hoving JL, Bartelds GM, Sluiter JK, et al. Perceived work ability, quality of life, and fatigue in patients with rheumatoid arthritis after a 6-month course of TNF inhibitors: prospective intervention study and partial economic evaluation. Scand J Rheumatol. 2009:1-5.

16. Breedveld FC, Weisman MH, Kavanaugh AF, et al. The PREMIER study: A multicenter, randomized, double-blind clinical trial of combination therapy with adalimumab plus methotrexate versus methotrexate alone or adalimumab alone in patients with early, aggressive rheumatoid arthritis who had not had previous methotrexate treatment. Arthritis Rheum. 2006;54(1):26-37.

17. Chen DY, Chou SJ, Hsieh TY, et al. Randomized, Double-blind, Placebo-controlled, Comparative Study of Human Anti-TNF Antibody Adalimumab in Combination with Methotrexate and Methotrexate Alone in Taiwanese Patients with Active Rheumatoid Arthritis. J Formos Med Assoc. 2009;108(4):310-319.

18. Weinblatt ME, Keystone EC, Furst DE, Kavanaugh AF, Chartash EK, Segurado OG. Long term efficacy and safety of adalimumab plus methotrexate in patients with rheumatoid arthritis: ARMADA 4 year extended study. Ann Rheum Dis. 2006;65(6):753-759.

19. Bourne T, Fossati G, Nesbitt A. A PEGylated Fab' fragment against tumor necrosis factor for the treatment of Crohn disease: exploring a new mechanism of action. BioDrugs. 2008;22(5):331-337.

20. Smolen JS, Landewe RB, Mease PJ, et al. Efficacy and Safety of Certolizumab Pegol Plus Methotrexate in Active Rheumatoid Arthritis: The RAPID 2 Study. Ann Rheum Dis. 2009;68(6):797-804.

21. Keystone E, Heijde D, Mason D Jr, et al. Certolizumab pegol plus methotrexate is significantly more effective than placebo plus methotrexate in active rheumatoid arthritis: findings of a fifty-two-week, phase III, multicenter, randomized, double-blind, placebo-controlled, parallel-group study. Arthritis Rheum. 2008;58(11):3319-3329.

22. Fleischmann R, Vencovsky J, van Vollenhoven RF, et al. Efficacy and safety of certolizumab pegol monotherapy every 4 weeks in patients with rheumatoid arthritis failing previous disease-modifying antirheumatic therapy: the FAST4WARD study. Ann Rheum Dis. 2009;68(6): 805-811. 
23. Keystone EC, Genovese MC, Klareskog L, et al. Golimumab, a human antibody to TNF-\{alpha $\}$ given by monthly subcutaneous injections, in active rheumatoid arthritis despite methotrexate: The GO-FORWARD Study. Ann Rheum Dis. 2009;68(6):789-786.

24. Kay J, Matteson EL, Dasgupta B, et al. Golimumab in patients with active rheumatoid arthritis despite treatment with methotrexate: a randomized, double-blind, placebo-controlled, dose-ranging study. Arthritis Rheum. 2008 Apr;58(4):964-975.

25. Keystone EC, Genovese MC, Klareskog L, et al. Golimumab, a human antibody to tumour necrosis factor \{alpha\} given by monthly subcutaneous injections, in active rheumatoid arthritis despite methotrexate therapy: the GO-FORWARD Study. Ann Rheum Dis. 2009;68(6): 789-796.

26. Seong SS, Choi CB, Woo JH, et al. Incidence of tuberculosis in Korean patients with rheumatoid arthritis (RA): effects of RA itself and of tumor necrosis factor blockers. J Rheumatol. 2007;34(4): 706-711.

27. Bongartz T, Sutton AJ, Sweeting MJ, Buchan I, Matteson EL, Montori V. Anti-TNF antibody therapy in rheumatoid arthritis and the risk of serious infections and malignancies: systematic review and meta-analysis of rare harmful effects in randomized controlled trials. JAMA. 2006;295(19):2275-2285.

28. Behnam SM, Behnam SE, Koo JY. TNF-alpha inhibitors and congestive heart failure. Skinmed. 2005 Nov-Dec;4(6):363-368.

29. Tsiodras S, Samonis G, Boumpas DT, Kontoyiannis DP. Fungal infections complicating tumor necrosis factor alpha blockade therapy. Mayo Clin Proc. 2008;83(2):181-194.

30. van der Meer JW, Popa C, Netea MG. Side effects of anticytokine strategies. Neth J Med. 2005;63(3):78-80.

31. Carter JD, Ladhani A, Ricca LR, Valeriano J, Vasey FB. A safety assessment of tumor necrosis factor antagonists during pregnancy: a review of the Food and Drug Administration database. J Rheumatol. 2009; 36(3):635-641.

32. Snoeckx Y GK, Sanders M, Gardiner M. Pregnancy Outcomes In Women Taking Infliximab: The Infliximab Safety Database. 2008 American College of Rheumatology Annual Scientific Meeting. San Francisco, CA; 2008.

33. Johnson DL KLJ, C Chambers. Pregnancy Outcomes for Women Exposed to Adalimumab: OTIS Autoimmune Diseases in Pregnancy Project. 2008 American College of Rheumatology Annual Scientific Meeting. San Francisco, CA; 2008.

34. Johnson DL KLJ, Chambers C. Pregnancy Outcomes in Women Exposed to Etanercept: The OTIS Autoimmune Diseases in Pregnancy Project. 2008 American College of Rheumatology Annual Scientific Meeting. San Francisco, CA; 2008.

35. Ramos-Casals M, Brito-Zeron P, Soto MJ, Cuadrado MJ, Khamashta MA. Autoimmune diseases induced by TNF-targeted therapies. Best Pract Res Clin Rheumatol. 2008;22(5):847-861.

36. Elezoglou A, Kafasi N, Kaklamanis PH, et al. Infliximab treatmentinduced formation of autoantibodies is common in Behcet's disease. Clin Exp Rheumatol. 2007;25(4 Suppl 45):S65-S69.

37. Kocharla L, Mongey AB. Is the development of drug-related lupus a contraindication for switching from one TNF alpha inhibitor to another? Lupus. 2009;18(2):169-171.

38. De Rycke L, Baeten D, Kruithof E, Van den Bosch F, Veys EM, De Keyser F. Infliximab, but not etanercept, induces IgM antidouble-stranded DNA autoantibodies as main antinuclear reactivity: biologic and clinical implications in autoimmune arthritis. Arthritis Rheum. 2005;52(7):2192-2201.

39. Tracey D, Klareskog L, Sasso EH, Salfeld JG, Tak PP. Tumor necrosis factor antagonist mechanisms of action: a comprehensive review. Pharmacol Ther. 2008;117(2):244-279.

40. Hyrich KL, Lunt M, Watson KD, Symmons DP, Silman AJ. Outcomes after switching from one anti-tumor necrosis factor alpha agent to a second anti-tumor necrosis factor alpha agent in patients with rheumatoid arthritis: results from a large UK national cohort study. Arthritis Rheum. 2007;56(1):13-20.
41. Karanikolas G, Charalambopoulos D, Vaiopoulos G, et al. Adjunctive anakinra in patients with active rheumatoid arthritis despite methotrexate, or leflunomide, or cyclosporin-A monotherapy: a 48-week, comparative, prospective study. Rheumatology (Oxford). 2008;47(9):1384-1388.

42. Mertens M, Singh JA. Anakinra for Rheumatoid Arthritis: A Systematic Review. J Rheumatol. 2009.

43. Dayer JM, Feige U, Edwards CK 3rd, Burger D. Anti-interleukin-1 therapy in rheumatic diseases. Curr Opin Rheumatol. 2001;13(3): 170-176.

44. Bresnihan B. Anakinra as a new therapeutic option in rheumatoid arthritis: clinical results and perspectives. Clin Exp Rheumatol. 2002; 20(5 Suppl 27):S32-S34.

45. Fleischmann RM. Addressing the safety of anakinra in patients with rheumatoid arthritis. Rheumatology (Oxford). 2003;42 Suppl 2: ii29-ii35.

46. Efthimiou P, Flavell RA, Furlan A, et al. Autoinflammatory syndromes and infections: pathogenetic and clinical implications. Clin Exp Rheumatol. 2008;26(1 Suppl 48):S53-S61.

47. Bingham CO 3rd. Emerging therapeutics for rheumatoid arthritis. Bull NYU Hosp Jt Dis. 2008;66(3):210-215.

48. Nowell MA, Richards PJ, Fielding CA, et al. Regulation of pre-B cell colony-enhancing factor by STAT-3-dependent interleukin-6 transsignaling: implications in the pathogenesis of rheumatoid arthritis. Arthritis Rheum. 2006;54(7):2084-2095.

49. Oldfield V, Dhillon S, Plosker GL. Tocilizumab: a review of its use in the management of rheumatoid arthritis. Drugs. 2009;69(5):609-632.

50. Jones G, Sebba A, Gu J, et al. Comparison of tocilizumab monotherapy versus methotrexate monotherapy in patients with moderate to severe rheumatoid arthritis: The AMBITION study. Ann Rheum Dis. 2009.

51. Nishimoto N, Miyasaka N, Yamamoto K, et al. Study of active controlled tocilizumab monotherapy for rheumatoid arthritis patients with an inadequate response to methotrexate (SATORI): significant reduction in disease activity and serum vascular endothelial growth factor by IL-6 receptor inhibition therapy. Mod Rheumatol. 2009;19(1):12-19.

52. Maini RN, Taylor PC, Szechinski J, et al. Double-blind randomized controlled clinical trial of the interleukin-6 receptor antagonist, tocilizumab, in European patients with rheumatoid arthritis who had an incomplete response to methotrexate. Arthritis Rheum. 2006;54(9):2817-2829.

53. Emery P, Keystone E, Tony HP, et al. IL-6 receptor inhibition with tocilizumab improves treatment outcomes in patients with rheumatoid arthritis refractory to anti-tumour necrosis factor biologicals: results from a 24-week multicentre randomised placebo-controlled trial. Ann Rheum Dis. 2008;67(11):1516-1523.

54. Nakamura I, Omata Y, Naito M, Ito K. Blockade of interleukin 6 signaling induces marked neutropenia in patients with rheumatoid arthritis. $J$ Rheumatol. 2009;36(2):459-460.

55. Edwards JC, Szczepanski L, Szechinski J, et al. Efficacy of B-celltargeted therapy with rituximab in patients with rheumatoid arthritis. NEngl J Med. 2004;350(25):2572-2581.

56. Cohen SB, Emery P, Greenwald MW, et al. Rituximab for rheumatoid arthritis refractory to anti-tumor necrosis factor therapy: Results of a multicenter, randomized, double-blind, placebo-controlled, phase III trial evaluating primary efficacy and safety at twenty-four weeks. Arthritis Rheum. 2006;54(9):2793-2806.

57. Emery P, Fleischmann R, Filipowicz-Sosnowska A, et al. The efficacy and safety of rituximab in patients with active rheumatoid arthritis despite methotrexate treatment: results of a phase IIB randomized, double-blind, placebo-controlled, dose-ranging trial. Arthritis Rheum. 2006 May;54(5):1390-1400.

58. Keystone E, Emery P, Peterfy CG, et al. Rituximab inhibits structural joint damage in patients with rheumatoid arthritis with an inadequate response to tumour necrosis factor inhibitor therapies. Ann Rheum Dis. 2009;68(2):216-221.

59. Finckh A, Ciurea A, Brulhart L, et al. B cell depletion may be more effective than switching to an alternative anti-tumor necrosis factor agent in rheumatoid arthritis patients with inadequate response to anti-tumor necrosis factor agents. Arthritis Rheum. 2007;56(5):1417-1423. 
60. Molloy ES, Calabrese LH. Progressive multifocal leukoencephalopathy in patients with rheumatic diseases: are patients with systemic lupus erythematosus at particular risk? Autoimmun Rev. 2008;8(2):144-146.

61. Boren EJ, Cheema GS, Naguwa SM, Ansari AA, Gershwin ME. The emergence of progressive multifocal leukoencephalopathy (PML) in rheumatic diseases. J Autoimmun. 2008;30(1-2):90-98.

62. Genovese MC, Kaine JL, Lowenstein MB, et al. Ocrelizumab, a humanized anti-CD20 monoclonal antibody, in the treatment of patients with rheumatoid arthritis: A phase I/II randomized, blinded, placebo-controlled, dose-ranging study. Arthritis Rheum. 2008;58(9): 2652-2661.

63. Coughlin M. Improving patient outlook in rheumatoid arthritis: experience with abatacept. J Am Acad Nurse Pract. 2008;20(10): 486-495.

64. Weinblatt M, Combe B, Covucci A, Aranda R, Becker JC, Keystone E. Safety of the selective costimulation modulator abatacept in rheumatoid arthritis patients receiving background biologic and nonbiologic disease-modifying antirheumatic drugs: A one-year randomized, placebo-controlled study. Arthritis Rheum. 2006;54(9): 2807-2816.

65. Kremer JM, Genant HK, Moreland LW, et al. Effects of abatacept in patients with methotrexate-resistant active rheumatoid arthritis: a randomized trial. Ann Intern Med. 2006 Jun 20;144(12):865-876.

66. Genovese MC, Becker JC, Schiff M, et al. Abatacept for rheumatoid arthritis refractory to tumor necrosis factor alpha inhibition. $N \mathrm{Engl}$ J Med. 2005;353(11):1114-1123.

67. Schiff M, Keiserman M, Codding C, et al. Efficacy and safety of abatacept or infliximab vs placebo in ATTEST: a phase III, multicentre, randomised, double-blind, placebo-controlled study in patients with rheumatoid arthritis and an inadequate response to methotrexate. Ann Rheum Dis. 2008;67(8):1096-1103.

68. Kremer JM, Genant HK, Moreland LW, et al. Results of a two-year followup study of patients with rheumatoid arthritis who received a combination of abatacept and methotrexate. Arthritis Rheum. 2008; 58(4):953-963.

69. Weinblatt M, Schiff M, Goldman A, et al. Selective costimulation modulation using abatacept in patients with active rheumatoid arthritis while receiving etanercept: a randomised clinical trial. Ann Rheum Dis. 2007;66(2):228-234.

70. Westhovens R, Robles M, Ximenes AC, et al. Clinical efficacy and safety of abatacept in methotrexate-naive patients with early rheumatoid arthritis and poor prognostic factors. Ann Rheum Dis. 2009 Jan 9. [Epub ahead of print].
71. Westhovens R, Kremer JM, Moreland LW, et al. Safety and efficacy of the selective costimulation modulator abatacept in patients with rheumatoid arthritis receiving background methotrexate: a 5-year extended phase IIB study. J Rheumatol. 2009 Apr;36(4):736-742.

72. Simon TA, Smitten AL, Franklin J, et al. Malignancies in the rheumatoid arthritis abatacept clinical development program: An epidemiological assessment. Ann Rheum Dis. 2008.

73. Bettelli E, Carrier Y, Gao W, et al. Reciprocal developmental pathways for the generation of pathogenic effector TH17 and regulatory T cells. Nature. 2006;441(7090):235-238.

74. Hwang SY, Kim HY. Expression of IL-17 homologs and their receptors in the synovial cells of rheumatoid arthritis patients. Mol Cells. 2005; 19(2):180-184.

75. Benderdour M, Tardif G, Pelletier JP, et al. Interleukin 17 (IL-17) induces collagenase-3 production in human osteoarthritic chondrocytes via AP-1 dependent activation: differential activation of AP-1 members by IL-17 and IL-1beta. J Rheumatol. 2002;29(6):1262-1272.

76. Koshy PJ, Henderson N, Logan C, Life PF, Cawston TE, Rowan AD. Interleukin 17 induces cartilage collagen breakdown: novel synergistic effects in combination with proinflammatory cytokines. Ann Rheum Dis. 2002;61(8):704-713.

77. Koenders MI, Joosten LA, van den Berg WB. Potential new targets in arthritis therapy: interleukin (IL)-17 and its relation to tumour necrosis factor and IL-1 in experimental arthritis. Ann Rheum Dis. 2006;65 Suppl 3 : iii29-iii33.

78. Scapini P, Nardelli B, Nadali G, et al. G-CSF-stimulated neutrophils are a prominent source of functional BLyS. J Exp Med. 2003;197(3):297-302.

79. Scapini P, Carletto A, Nardelli B, et al. Proinflammatory mediators elicit secretion of the intracellular B-lymphocyte stimulator pool (BLyS) that is stored in activated neutrophils: implications for inflammatory diseases. Blood. 2005;105(2):830-837.

80. Tan SM, Xu D, Roschke V, et al. Local production of B lymphocyte stimulator protein and APRIL in arthritic joints of patients with inflammatory arthritis. Arthritis Rheum. 2003;48(4):982-992.

81. Cheema GS, Roschke V, Hilbert DM, Stohl W. Elevated serum B lymphocyte stimulator levels in patients with systemic immune-based rheumatic diseases. Arthritis Rheum. 2001;44(6):1313-1319.

82. Treml JF, Hao Y, Stadanlick JE, Cancro MP. The BLyS family: toward a molecular understanding of B cell homeostasis. Cell Biochem Biophys. 2009;53(1):1-16.

83. Scott DL, Cope A. New tumour necrosis factor inhibitors for rheumatoid arthritis: are there benefits from extending choice? Ann Rheum Dis 2009;68(6):767-769.
Biologics: Targets \& Therapy

\section{Publish your work in this journal}

Biologics: Targets \& Therapy is an international, peer-reviewed journal focusing on the patho-physiological rationale for and clinical application of Biologic agents in the management of autoimmune diseases, cancers or other pathologies where a molecular target can be identified. This journal is indexed on PubMed Central, CAS,

\section{Dovepress}

EMBase, Scopus and the Elsevier Bibliographic databases. The manuscript management system is completely online and includes a very quick and fair peer-review system, which is all easy to use. Visit http://www.dovepress.com/testimonials.php to read real quotes from published authors. 